\title{
Feed the Tree: Representation of Australia-based Academic Women at $\mathrm{HCl}$ Conferences
}

Dana McKay

iSchool, University of Melbourne, dana.mckay@unimelb.edu.au

George Buchanan

iSchool, University of Melbourne, george.buchanan@unimelb.edu.au

Conference attendance is an important part of any career in academic computing, facilitating both the citations that are key for academic advancement, and the networking opportunities that result in job and collaboration opportunities. For some authors, though, the barriers to participation in academic conferences are significant: beyond having a paper accepted, logistical considerations around care responsibilities and financial considerations may limit participation. One axis along which these barriers become particularly obvious is gender: barriers to conference participation, particularly in distant locations, are higher for women, resulting in negative career impacts. Previous research established that women make up $41 \%$ of the authors for OzCHI in the five years from 2014-19, but how does this compare to other major conferences in HCI, such as CHI and DIS? We use a scientometric analysis to examine this question in this paper, finding that Australiabased women are under-represented in these conferences. This is likely to result in negative effects on the careers of female HCI academics in Australia, whether they remain here or attempt to find work abroad.

CCS CONCEPTS - Social and professional topics User characteristics Gender - Social and professional topics Professional topics Computing industry Industry statistics • Social and professional topics Professional topics Computing profession $\sim$ Employment issues $\bullet$ Human-centered computing Human computer interaction (HCI)

\section{ACM Reference Format:}

First Author's Name, Initials, and Last Name, Second Author's Name, Initials, and Last Name, and Third Author's Name, Initials, and Last Name. 2018. The Title of the Paper: ACM Conference Proceedings Manuscript Submission Template: This is the subtitle of the paper, this document both explains and embodies the submission format for authors using Word. In Woodstock '18: ACM Symposium on Neural Gaze Detection, June 03-05, 2018, Woodstock, NY. ACM, New York, NY, USA, 10 pages. NOTE: This block will be automatically generated when manuscripts are processed after acceptance.

\section{Introduction}

The myth of meritocracy is highly prevalent in both technology and academia, resulting in significant disadvantages in these fields for women. In fact, academics are assessed by metrics such as citation rates (and statistics such as the h-index that rely on them) and teaching evaluation scores that are demonstrably biased $[\underline{5} ; \underline{11} ; \underline{13} ; \underline{20}]$. One potential driver of bias in computing fields is the use of conference publications, and the opportunities derived from conferences (such as networking) to assess merit. It is well known that conferences present logistical challenges for those with care or heavy teaching responsibilities (often women), and that research funding also limits participation. We already have a baseline for women's participation in HCI conferences in Australia, we addressed this in our previous paper. How does this translate to an international scene, though, where papers are accorded high prestige, and key collaborations are formed, thus shaping the future of Australian HCI? 
Some might argue that a lack of diversity is unimportant, reflecting a lack of aptitude or interest, a common argument in technology fields [40]. Others will concede that diversity is important, but insist that in fact brilliance is more important than diversity. This argument is common in heavily male dominated fields, tech among them [23]. These arguments are belied by the fact that financial outcomes, design quality, team performance and accessibility are all improved by having diverse teams [37]. Traditionally HCI has followed technology in its gender bias: the top 20 most frequent $\mathrm{CHI}$ authors of all time, for example, includes only a single woman (Wendy E. Mackay, in position 20) ${ }^{1}$. When we take the past 5 years, however, this list includes 5 women, the first appearing in position 8 . We argue that diversity is key in HCI research, mitigating against 'I-methodology' bias (bias introduced by designing predominantly for oneself, whether this is a result of having a single designer or a strongly homogenous team [7]. Teams lacking in diversity are more likely to produce technologies that do not work for all users, such as discriminatory facial and voice recognition systems, mobile phones that are too big for women's hands, and virtual reality systems that are more likely to make women ill [31]. Quality outcomes are not the only reason for ensuring HCI as a field is diverse and representative, though. Australian HCI is governed by two major bodies: the Human Factors and Ergonomics Society of Australia, which is the overseeing body for OzCHI, and the ACM, which publishes both DIS and CHI. Each of these organizations has a code of ethics that calls for diversity and equal representation in the functions of the society: to discriminate, directly or indirectly, contravenes the code of ethics of these bodies.

It is difficult to address diversity challenges without information: we need to know what biases exist and why to counteract them. We follow the scientometric method from a previous paper [25], but apply it to authorship at two other major HCI conferences: DIS (Designing Interactive Systems) and CHI. Disadvantage in both technology and academia exists along other axes than gender: race, religion, sexuality, nationality and many other characteristics also negatively affect careers, particularly where they intersect [45]. In this paper we follow up a publication from last year's OzCHI addressing gender in Australian HCI [25]. Like that previous paper we focus on gender, not because it is more important than other characteristics, but because it is readily and publicly available. While some people are very open about protected characteristics such as sexuality, disability, and cultural and religious background, we cannot easily determine the identities of all authors on these axes. Gender, in contrast, is much more readily discerned, if not perfectly captured.

We use a scientometric approach to demonstrate that for international HCI conferences, Australia based female academics are under-represented in author lists as a whole, though this is less pronounced for the key first author role. We further show that the Australian authorship profile at these conferences is less gender-balanced than is typical of the conferences as a whole. These factors are likely to limit the careers of Australia-based female HCI scholars. Arguably, we could have published this work in a scientometrics-focused venue but our preferred audience for these findings is the $\mathrm{OzCHI}$ community. We consider that these findings should be addressed by our community as a matter of urgency.

\section{Background Literature}

In this section, we first address address the well-known challenges faced by women in technology generally, focusing particularly on the pipeline problem. Next, we discuss the myth of meritocracy, and how academia perpetuates it. Thirdly we address the benefits and drawbacks of conferences as a means of publication. We focus primarily on the experience of women, but do not restrict our understanding of this to cis-women alone. We point to known points of differences between women's experiences where there is established research literature to illuminate them.

\subsection{Women in Technology and $\mathrm{HCl}$}

The challenges faced by women in technology are well documented, both in and out of academia $[21 ; \underline{24} ; \underline{33}]$. Women enter technology education at lower rates than men, and leave the field at higher rates than men, resulting in ever fewer women along the career pipeline. Many of the reasons for this are social: women struggle to feel they are getting ahead in their careers, and the 'brogrammer' culture of many computing initiatives is alienating to them [42]. The single-minded focus perceived in technology fields to represent 'brilliance' is not how women demonstrate their interest in computing, with further limits their opportunities $[24 ; \underline{31}$. The pipeline problem also exists in academic computing, few of the

\footnotetext{
${ }^{1}$ https://dl.acm.org/conference/chi/authors
} 
professoriat are women, and a recent paper shows a decreasing proportion of women authors by career stage in HCI and Machine Learning [12].

A range of initiatives have begun to address this challenge, examining how to make computing education more equitable. Some of these initiatives have even come from within HCI, including work on the differences between boys' and girls' preferences in programming education [3] .

Surprisingly, though, for a field that has a feminist subdiscipline [34], and which has been focused on providing universal access to technology for 20 years or more, there has been little reflection on equity in our own field. A 2018 paper addressing author order in HCI and Machine Learning is a notable exception [12], it found that women were experiencing bias in HCI: they were less likely to be in the prestigious 'last author' position on publications, and had negative experiences of negotiating author order with male colleagues [12]. Another exception is the paper presented at last year's OzCHI, which paints a much rosier picture: generally speaking the authorship profile at OzCHI is representative of the current state of the field as a whole [25].

In this paper we aim to further address this dearth of work on equity in HCI, examining the representation of women at international conferences in HCI.

\subsection{The Myth of Academic Meritocracy and the Academic Experiences of Women}

The myth of meritocracy is prevalent in academia [28], assuming that the metrics used to evaluate academics: publications, grant income, and teaching evaluations are non-discriminatory. In fact, when presented with true scientific evidence that academia has practices that are inherently biased, and false evidence that academia is non-biased, male scientists evaluate the false science as more plausible [15]. This picture is far from the truth. Women find it harder to find the mentors in academia that are so necessary both for guidance, and for letters of recommendation [27]. When they do get letters of recommendation, these letters express women's experience and accomplishments differently than men's, using words like 'hardworking' to describe women, and 'brilliant' to describe men [31].

Less relevant to this work, though still salient to the experiences of women in academia, are women's teaching evaluations. Women receive worse evaluations for the same teaching as men, even when the teaching is identical, because half the class have been deceived into believing that a female teacher is male [ $\underline{]}$. As with letters of recommendation, personal comments in teaching evaluations are rife, and women have to walk the fine line of being approachable and authoritative at the same time [31]. Research has already established that trans-women's experience frequently mirrors that of cis-women, but has particular challenges that vary between social contexts [26].

Turning to the domain of research and how merit is assessed in it, many measures are biased. Publication is one measure of the value of a researcher: women are less likely to be published than men due to bias in peer review, particularly single-blind review [17; 39]. This finding holds true over a range of disciplines. When women do successfully publish, they receive less prestigious positions on author lists [녀], and less credit for the work they have done than men in author lists unless they author exclusively with other women [22]. Once published, women are less likely to be cited than men [13], and less likely to cite themselves [20], driving key indicators such as their h-indexes lower than men's. Women are also less likely to have the time to do research: female academics report spending more time on family-related tasks, academic service (particularly the non-prestigious kinds, such as the equity committee), and teaching than men $[14 ;$ 31]. A further recognition of research prowess is funding: women are less likely to receive funding than men, particularly where 'investigator quality' is a key metric $[1 ; \underline{6}]$. This in turn prevents them from buying themselves out of teaching duties, further exacerbating the time issues highlighted above.

With the issues of teaching and research evaluation taken together, it is clear that academia is far from being a meritocracy, and that women is one group that experiences bias. Other groups include racial and ethnic minorities, those with a disability, and those from low socioeconomic backgrounds, to name just a few of the many characteristics that can result in bias. To address all of these issues across every academic field in every country would be a very large undertaking indeed. Instead we focus on the issue of gender, as it is readily publicly discernible, and HCI, as our own discipline. For this paper we focus explicitly on Australian HCI, because as members of the community, this is where we feel we can make the most difference. 


\subsection{The Positives and Negatives of Academic Conferences}

Conferences are the primary means of publication in HCI, as they are in many computing disciplines. There are significant benefits to publishing at conferences, and some of these benefits increase with the prestige of the conference. One such benefit is accruing the citations needed to demonstrate one is an effective researcher: the average CHI paper, for example, is cited 17 times $^{2}$; DIS $10^{3}$, and OzCHI $5^{4}$. Conferences result in increased collaborations when investigated both qualitatively [16] and quantitatively [41], and afford opportunities for networking that can lead to job offers and other prestigious invitations [36].

Conference attendance is not an equal-opportunity sport, however. Those with care responsibilities (disproportionately women) find it harder to attend conferences, as do those with heavy teaching loads (also disproportionately women) [38]. Further, conference attendance is limited to those who can fund it. Obviously, conferences in expensive locations or those that are far from home are more expensive to attend, and thus more difficult to fund. The financial barrier is particularly pointed for those who, for reasons of care responsibilities or disability must travel with another person, so while childcare at conferences addresses one problem, it exacerbates another. As noted above, women receive less research funding than men [31], so are less likely to be able to fund conference travel at their own discretion. Departmental funding or scholarship funding in Australia is often tied to conference prestige, so those without discretionary funding can only attend the most prestigious conferences.

Taken together this paints a picture of a professional activity with significant benefits that is more accessible to those with money and without care responsibilities, more often men. In this paper we address whether this holds true for international conferences for Australian HCI academics.

\section{Methodology}

As with the previous $\mathrm{OzCHI}$ paper on this issue, we took a scientometric approach to analysis of Australia-based gender representation in HCI conferences. Scientometrics is a commonly used approach to addressing equity issues, particularly on issues of gender and geography $[\underline{2} ; \underline{4} ; \underline{12}]$, both of which this paper addresses. We focused specifically on conferences, because differential access to them has a disproportionately large impact: it affects not just citation, but also professional networking opportunities. We focused on OzCHI, being the local Australian conference, and DIS and CHI, two international generalist conference venues in HCI. All venues have double-blind peer review, limiting discrimination against women in the review process, and DIS and CHI have similar acceptance rates, hovering around 23-24\% each year $^{1,2}$. The major difference between DIS and CHI for Australian scholars is their CORE ranking: DIS is ranked, B (in the top $29 \%$ of venues for the field), CHI A* (top 7\%). For many academics at Australian institutions, particularly those without access to discretionary funds, this difference means that travel to $\mathrm{CHI}$ is considerably easier to secure funding for than travel to DIS.

In examining these author lists, we counted the presence of authors based in Australia in any position in the author list, and counted Australia based first authors particularly. We did this using affiliation data from the paper, so where someone has moved during the sample period, they are only counted as an Australian author where they report an Australian affiliation. Similarly, for authors with strong associations with more than one country during the sample period, the affiliation used on each paper is respected. We did not encounter any examples of double affiliations, but had we done so the first affiliation would have been used for our analysis. We did not distinguish in our analysis between papers authored entirely by Australia-based authors and international collaborations, all authorships by Australia-based authors are counted.

Once we had identified Australian authors, we divided authorships by gender. We counted each paper as a separate authorship, as would be typical of performance assessment and citation metrics. We used a social construction of gender, as adopted by previous work $[2 ; \underline{4} ; \underline{12}]$, assessing he gender presentation of the authors as expressed on their professional or institutional website, categorizing those using 'he/him' descriptors as men, and 'she/her' as women. We did not

\footnotetext{
${ }^{2}$ https://dl.acm.org/conference/chi

${ }^{3}$ https://dl.acm.org/conference/dis

${ }^{4}$ https://dl.acm.org/conference/ozchi
} 
encounter any author who publicly identified as non-binary, used 'they/their' to refer to themselves, or otherwise expressed an identity in the gender-diverse spectrum outside the conventional gender binary. We did not encounter any Australia-based author for whom we could not find any gender signifiers. As with the prior research that has used the same method, we made no investigation into an authors previous gender identities or biology. As mentioned in $\underline{\text { Section }}$ $\underline{2.2}$ above, many of the disadvantages experienced by women are experienced by trans and cis women alike, as a result of their social gender presentation [26].

Clearly, we cannot identify a researcher's personal experience of gender through our method, and this caveat should be borne in mind throughout the paper. As has been noted in previous research, determining gender from photographic material is problematic, especially when automated, and the range of gender identities and experiences are not wellcaptured by the conventional gender binary [19]. The lack of identifiable gender-diverse and non-binary authors in Australian HCI suggests that our discipline may have participation barriers for these groups and we should consider whether there are ways we could make our field more accessible to these scholars. The binary frame of reporting used in the remainder of the paper is a consequence of our data, not a methodological presumption.

Finally, to get a baseline to compare Australian gender balance against international gender balance at these conferences, for each conference we selected a sample of 30 papers from first authors based in Europe or North America. We then counted male and female authors and first authors on each. A separate, unpublished analysis has shown a significant skew toward male authors in publications from institutions in Asia and the middle east, so we excluded these papers from our sample.

Once we had our data, we compared gender balance for Australian first authors and overall authorship at OzCHI, DIS and CHI. We present these results in the next section.

\section{Results}

We first report summary data for OzCHI from 2016 to 2019 in Table 1 below - the same years as the data for both CHI and DIS. We give the total number of authors (first two data columns), the number of co-authors (second pair), and finally the first authors, giving totals of men and women respectively in each pair of columns.

Table 1: Australian Authors at OzCHI 2016-2019

\begin{tabular}{clcccccc}
\hline Year & Location & \multicolumn{2}{c}{ All Authors } & \multicolumn{2}{c}{ Co-Author } & \multicolumn{2}{c}{ First Authors } \\
\hline & & Men & Women & Men & Women & Men & Women \\
\hline 2016 & Launceston, TA & 33 & 17 & 24 & 11 & 9 & 6 \\
2017 & Brisbane, QLD & 34 & 29 & 26 & 21 & 8 & 8 \\
2018 & Melbourne, VIC & 30 & 18 & 21 & 15 & 9 & 3 \\
2019 & Perth, WA & 27 & 25 & 19 & 20 & 8 & 5 \\
Total & & 124 & 89 & 90 & 67 & 34 & 22 \\
\hline
\end{tabular}

This data provides a baseline to understand the relative representation of men and women Australian authors in the international venues. The cumulative data for CHI from 2016 to 2019 is presented in Table 2 below.

Table 2: Australian Authors at CHI 2016-2019

\begin{tabular}{|c|c|c|c|c|c|c|c|}
\hline \multirow[t]{2}{*}{ Year } & \multirow[t]{2}{*}{ Location } & \multicolumn{2}{|c|}{ All Authors } & \multicolumn{2}{|c|}{ Co-Author } & \multicolumn{2}{|c|}{ First Authors } \\
\hline & & Men & Women & Men & Women & Men & Women \\
\hline 2016 & San José, USA & 20 & 8 & 11 & 5 & 9 & 3 \\
\hline 2017 & Denver, USA & 52 & 17 & 42 & 13 & 10 & 4 \\
\hline 2018 & Toronto, Can. & 20 & 11 & 12 & 7 & 8 & 4 \\
\hline 2019 & Glasgow, UK & 85 & 33 & 71 & 21 & 14 & 12 \\
\hline Total & & 177 & 69 & 136 & 46 & 41 & 23 \\
\hline
\end{tabular}


In total there have been 64 first-authored Australian papers at $\mathrm{CHI}$ in these four years. In terms of first authors, there were 41 men (64.1\%) and 23 women (35.9\%). This differs only slightly from the OzCHI proportions of $60.7 \%$ and $39.3 \%$. Unsurprisingly, this difference is clearly not reliable when tested with Pearson's chi-squared test, with $\mathrm{p}=0.705$ $\left(\chi^{2}=0.143, \mathrm{df}=1\right)$.

Turning next to all Australian authors, the totals are 177 men (72.0\%) and 69 women (28.0\%). Almost all appear on Australian first-authored works. This is in a sharp contrast with the $58.2 \%$ and $41.8 \%$ seen at OzCHI. This difference is very reliable, with $\mathrm{p}=0.0021\left(\chi^{2}=9.54, \mathrm{df}=1\right)$. When we consider co-authors (i.e. second or later placed authors only), the totals are 136 men (74.7) and 46 women $(25.3 \%)$ with $\mathrm{p}=0.00071\left(\chi^{2}=11.45, \mathrm{df}=1\right)$.

Therefore, for CHI versus OzCHI, while we see a modest drop in women's representation that is not statistically reliable for first authors, there is a sharp change in the case of complete author lists, which is more reliable if only second, or later, placed authors are evaluated.

Having considered CHI, we now present the case for the DIS conference (see Table 3). At DIS, there have been 14 papers first-authored by men $(73.7 \%)$ and $5(26.3 \%)$ by women. This is a superficially larger difference than with $\mathrm{CHI}$. However, with fewer data points, there is a fair chance of a test not yielding a reliable result. Indeed, this proves to be the case with different $\left(\chi^{2}=1.04, \mathrm{p}=0.309, \mathrm{df}=1\right)$.

Table 3: Australian Authors at DIS 2016-2019

\begin{tabular}{|c|c|c|c|c|c|c|c|}
\hline \multirow[t]{2}{*}{ Year } & \multirow[t]{2}{*}{ Location } & \multicolumn{2}{|c|}{ All Authors } & \multicolumn{2}{|c|}{ Co-Author } & \multicolumn{2}{|c|}{ First Authors } \\
\hline & & Men & Women & Men & Women & Men & Women \\
\hline 2016 & Brisbane, Aus & 36 & 17 & 31 & 14 & 5 & 3 \\
\hline 2017 & Edinburgh, UK & 6 & 1 & 4 & 1 & 2 & 0 \\
\hline 2018 & Hong Kong, CN & 8 & 2 & 6 & 1 & 2 & 1 \\
\hline 2019 & California, USA & 17 & 8 & 12 & 7 & 5 & 1 \\
\hline Total & & 67 & 28 & 53 & 23 & 14 & 5 \\
\hline
\end{tabular}

The results for all authors again show a marked contrast with $\mathrm{OzCHI}$, with there being 67 authors who are men $(70.5 \%)$ and 28 women (29.5\%). Again, the smaller number of data points may encourage caution. However, the result is reliable with $\mathrm{p}=0.040\left(\chi^{2}=4.226, \mathrm{df}=1\right)$. For co-authors only the totals are 53 men $(69.7 \%)$ and 23 women $(30.3 \%)$, with $\mathrm{p}=0.013\left(\chi^{2}=6.20, \mathrm{df}=1\right)$. Combining the $\mathrm{CHI}$ and DIS series did not produce any change in reliable effects.

Overall, while there is a drop in first authorships, this is not a reliable effect, and the likelihood is that even if this effect is not due to mere chance, the power of the effect is low. In contrast, there is a marked effect that males are much more likely to be present as co-authors in submissions to both CHI and DIS. This is not true of OzCHI, and this suggests that different practices are at play for the different venues.

\section{Discussion}

Our data shows that when it comes to being a co-author, Australian women researchers are surprisingly underrepresented compared to their male peers. From the previous research, it might be expected for first-author rates by Australian woman researchers to drop, this is at most a marginal effect, and none of the data available supports any hypothesis based on that expectation.

The under-representation amongst co-authors may, nonetheless, represent the visible barriers to participation that have been suggested in the prior literature. There are multiple potential factors that may lead to women being less represented among co-authors on a paper. The first possible explanation is resources: where a researcher is less able to afford the resources needed to attend the conference in person, whether due to financial, practical or other constraints, this may serve as a disincentive to volunteer as an author [38]. A second possibility is that in parts of the community, women are less likely to be invited to join in the research that leads to a paper. Consequently, while represented in the expected proportion in some research groups, they may be under-represented in others as co-authors, as noted by [12]. Rather than the issue of resources, this is due to implicit or explicit exclusion by other, male, researchers. A third option is an indirect effect of topic, where particular topics are more likely to have a greater number of authors, and that those 
topics are primarily researched by men. Fourthly, as noted in the background, there may be a feedback loop in play, where a lack of opportunity to attend in a previous year leads to a lowered opportunity in the following year [16; 41$]$. Further options include stage in career (e.g. fewer women researchers being senior), or the researcher being in academia or industry at the time of the publication. A previous evaluation of the career stage balance in Australian HCI researchers (e.g.[25]), provided little evidence for a clear impact from seniority on authorship, but a detailed analysis could ensure there are no interaction effects, e.g. challenges in mid-career, that are obscured by a simple senior/early career split.

Of course, any one of these factors may be at play, or indeed all of them. Careful investigations are needed to understand the causes of this lower representation of female researchers. Given the established feedback loops on opportunity, this is likely to impact the ability of female researchers to secure posts and promotions, and itself lead to entrenched disadvantage [36].

Finally 2020 and the COVID-19 pandemic will provide yet another set of data and perspectives. There is considerable evidence that overall women are authoring less during the pandemic, while men's productivity has gone up [30; 32]. Care of small children is one explanatory factor, but not a complete explanation for this pattern. Online conferences might mitigate against some of the largest challenges of travel, such as care and cost [35], but not travelling means that one is also expected to work a normal day, in addition to conference attendance [18]. Further, for those of us in Australia, conferences held in Europe or on the east coast of North America are being held at times that are incompatible with working during normal hours, if one is to sleep. Longitudinally, the reduced opportunities to socialize at online conferences may level the playing field somewhat; conversely it will increase the advantage of being socially forthright and already having connections [8]. We simply do not know yet what the effects of COVID-19 will be, however it is key that we continue to watch and monitor this space, to ensure women are not disproportionately disadvantaged by the changes wrought.

\section{Future Work}

This paper has discerned differences in the gender representation of Australian researchers in the author lists of papers at two international HCI conferences. Much more could be done to analyse how widespread this is - e.g. considering specialist HCI venues such as UbiComp, MobileHCI, and also technically focussed conferences with a significant HCI component, such as the ACM/IEEE Joint Conference on Digital Libraries, or the Conference on Human Information Interaction and Retrieval (CHIIR). However, there are factors that could be influencing the picture drawn here that we could investigate with the currently available data. For one, the location of the venue may be playing a part. This could be tested by considering conferences held in Australia (e.g. DIS 2016) or nearby (e.g. DIS 2018), but the lack of data points will require careful consideration of the evaluation method to use.

A quantitative approach could be applied to test whether particular research groups have a stronger representation of women, or amongst whom female researchers are less likely to be included in author lists, particularly as co-authors. Marginalisation is a product of group culture, and like plagiarism may in fact be relatively rare, but pervasive in local groups $[\underline{9} ; \underline{10}]$. This could be a factor at play in Australia, as elsewhere. Due to concerns of privacy and the anonymity of the review process, we do not have information on the number of submissions from those identifying as male or female, and hence if there are barriers within or before the review process. Concrete data here could allow a closer identification of whether differences emerge before, during or after the review process: something that publication data alone cannot interrogate.

A qualitative approach could help uncover the factors at play more directly, perhaps drawing on the work of [38] who indicate some factors that influence conference attendance amongst early career researchers. For example, the time taken to attend an overseas conference can be a disincentive. These sorts of factors would not readily fall to further numerical analysis alone. Given the relatively small size of the Australian HCI community, we can identify presented gender relatively easily, being Australian HCI researchers ourselves. However, gender is a multi-faceted issue, and those presenting as a particular gender may experience more or less congruity with their public persona; have experiences and opportunities that stem from other factors such as social group, ethnicity or race; we know that in almost every study that examines intersectional diversity, having more than one protected characteristic results in higher rates of disadvantage $[\underline{31} ; \underline{43}]$. Examining the complexity of identity through interviews would likely provide a more sophisticated and 
complex account that better captures researchers' personal experiences. Interviews could also allow a better understanding of how factors such as family commitments, institutional contexts, stage of career or research area influence academics' submissions to and participation at conferences. Again, qualitative data may transform our understanding.

Whether qualitative or quantitative, further work to examine inter-sectional issues, the experience of trans, genderconforming, those in transition, and the specific experiences that stem from socio-economic position, race, ethnicity, or the age of commencing a research career are all areas where further investigations are needed. It is well-established that Aboriginal and Torres Strait Islander people are under-represented in Australian Higher Education, and this would be one example area where interrogating our life as an HCI community would be worthwhile [44].

However, understanding the factors at play does not necessarily lead to change. The mechanisms that provide funding and other support for conference attendance can be opaque, and a lack of accountability is known to be associated with poor practice [12]. Australian standards here fall behind those of other developed countries, where monitoring is legally required, as part of equality legislation. Voluntary protocols to ensure greater transparency and provide more rapid detection of inequalities should be designed and implemented by organisations that wish to facilitate change. An example would be for research groups to publish summary data on the support provided to researchers, which would reveal percapita biases for or against either sex.

A lack of inclusion has been shown to lead to defective designs that have tangible social impacts, including for example even buildings meet the needs of women poorly [29], and the design of mobile technologies that are significantly less usable for women [31]. For HCI to achieve its maximum impact on Australian industry and society, reforming a defective and unrepresentative model of research is a necessity, not an option.

\section{Conclusions}

In this paper we have compared Australian authorship at international HCI conferences to authorship at OzCHI, looking specifically at the issue of gender representation in author lists. While women appear as first authors in roughly equal proportions at $\mathrm{OzCHI}$ and overseas, more prestigious conferences, the complete author lists tell a different story. Men make up a much greater proportion of the overall author lists at CHI and DIS than they do at OzCHI. There are many possible reasons for this, including long author lists in male dominated subfields, and nepotism in co-authorship selection: which reasons are in play is unclear from our analysis. What is clear, is that Australian women in HCI are being underrepresented at prestigious international conferences. This underrepresentation in turn is likely to have long term negative impacts on the careers of women in HCI in Australia: not being represented at or attending conferences lowers one's credibility in the field, and reduces one's opportunity for citation in HCI. If we want to include women fully in Australian HCI - and we should, for ethical reasons but also because diverse teams produce better designs - we must address the international authorship disparity as a matter of urgency.

\section{ACKNOWLEDGMENTS}

We thank the anonymous reviewers of this paper for their generous suggestions and ideas.

\section{REFERENCES}

$\langle$ bib id="bib1" $><$ number $>[1]</$ number $>$ Albers, C.J., 2015. Dutch research funding, gender bias, and Simpson's paradox. Proceedings of the National Academy of Sciences 112, 50, E6828-E6829. DOI= http://doi.org/10.1073/pnas.1518936112.</bib>

$<$ bib id="bib2" $><$ number $>[2]</$ number $>$ Bartneck, C. and Hu, J., 2010. The fruits of collaboration in a multidisciplinary field. Scientometrics 85,1 (2010/10/01), 41-52. DOI= http://doi.org/10.1007/s11192-010-0242-4.</bib $>$

<bib id="bib3"><number>[3]</number>Beckwith, L., Kissinger, C., Burnett, M., Wiedenbeck, S., Lawrance, J., Blackwell, A., and Cook, C., 2006. Tinkering and gender in end-user programmers' debugging. In Proc Proceedings of the SIGCHI Conference on Human Factors in Computing Systems CHI 06 (Montreal, Quebec, Canada), ACM, 231-240. DOI= http://doi.org/10.1145/1124772.1124808.</bib>

$<$ bib id="bib4" $><$ number $>[4]</$ number $>$ Bogers, T. and Greifeneder, E., 2016. The iSchool community: A case study of iConference Reviews. In Proc IConference 2016 iConference 16 (Pittsburgh, PA), iSchools. DOI= http://doi.org/10.9776/16247.</bib>

$<$ bib id="bib5" $><$ number $>[5]</$ number $>$ Boring, A., 2017. Gender biases in student evaluations of teaching. Journal of public economics 145, 27-41.</bib > $<$ bib id="bib6" $><$ number $>[6]</$ number $>$ Breen, G., 1997. Nepotism and sexism in peer-review. Nature 389, 6649 (1997/09/01), 326-326. DOI= http://doi.org/10.1038/38594.</bib> 
<bib id="bib7"><number>[7]</number>Breslin, S. and Wadhwa, B., 2018. Gender and Human-Computer Interaction. In The Wiley Handbook of Human Computer Interaction, K. Norman and J. Kirakowski Eds. Wiley, 71-87.</bib $>$

$<$ bib id="bib8" $><$ number $>[8]</$ number $>$ Brown, B., 2020. Notes on running an online academic conference or how we got zoombombed and lived to tell the tale. interactions $27,16-21$. DOI $=$ http://doi.org/10.1145/3406108. $</$ bib $>$

$<$ bib id="bib9" $><$ number $>[9]</$ number $>$ Buchanan, G. and McKay, D., 2017. The Lowest Form of Flattery: Characterising Text Re-Use and Plagiarism Patterns in a Digital Library Corpus. In Proc 2017 ACM/IEEE Joint Conference on Digital Libraries (JCDL) JCDL 17 (Toronto, Canada), 1-10. DOI= http://doi.org/10.1109/JCDL.2017.7991570.</bib>

$<$ bib id="bib10" $><$ number $>[10]</$ number $>$ Buchanan, G. and McKay, D., 2018. Leader of the pack: On plagiarism prevention through research group enculturation. Proceedings of the Association for Information Science and Technology 55, 1, 39-48. DOI= http://doi.org/10.1002/pra2.2018.14505501006.</bib>

<bib id="bib11"><number>[11]</number>Ceci, S.J., Ginther, D.K., Kahn, S., and Williams, W.M., 2014. Women in Academic Science: A Changing Landscape. Psychological Science in the Public Interest 15, 3 (2014/12/01), 75-141. DOI= http://doi.org/10.1177/1529100614541236.</bib> <bib id="bib12"><number>[12]</number>Early, K., Hammer, J., Hofmann, M.K., Rode, J.A., Wong, A., and Mankoff, J., 2018. Understanding Gender Equity in Author Order Assignment2, CSCW \%J Proc. ACM Hum.-Comput. Interact., Article 46. DOI= http://doi.org/10.1145/3274315.</bib> $<$ bib id="bib13" ><number $>[13]</$ number $>$ Ferber, M.A. and Brün, M., 2011. The Gender Gap in Citations: Does It Persist? Feminist Economics 17, 1 (2011/01/01), 151-158. DOI= http://doi.org/10.1080/13545701.2010.541857.</bib >

<bib id="bib14" $><$ number $>[14]</$ number $>$ Guarino, C.M. and Borden, V.M., 2017. Faculty service loads and gender: Are women taking care of the academic family? Research in Higher Education 58, 6, 672-694.</bib $>$

$<$ bib id="bib15" ><number $>[15]</$ number $>$ Handley, I.M., Brown, E.R., Moss-Racusin, C.A., and Smith, J.L., 2015. Quality of evidence revealing subtle gender biases in science is in the eye of the beholder112,43, 13201-13206. DOI= http://doi.org/10.1073/pnas.1510649112\%J Proceedings of the National Academy of Sciences. $</$ bib $>$

$<$ bib id="bib16" ><number $>[16]</$ number $>$ Harrison, R.J.T.S.L., 2010. Unique benefits of conference attendance as a method of professional development for LIS professionals59, 3-4, 263-270.</bib $>$

<bib id="bib17" ><number $>[17]</$ number $>$ Kaatz, A., Gutierrez, B., and Carnes, M., 2014. Threats to objectivity in peer review: the case of gender. Trends in pharmacological sciences 35, 8, 371-373. DOI= http://doi.org/10.1016/j.tips.2014.06.005.</bib >

$<$ bib id="bib18" $><$ number $>[18]</$ number $>$ Kalia, V., Srinivasan, A., Wilkins, L., and Luker, G.D., 2020. Adapting Scientific Conferences to the Realities Imposed by COVID-19. Radiology. Imaging Cancer 2, 4. DOI= http://doi.org/10.1148/rycan.2020204020.</bib>

<bib id="bib19" ><number $>[19]</$ number $>$ Keyes, O., 2018. The Misgendering Machines: Trans/HCI Implications of Automatic Gender Recognition. Proc. ACM Hum.-Comput. Interact. 2, CSCW, Article 88. DOI= http://doi.org/10.1145/3274357.</bib >

<bib id="bib20" ><number>[20]</number>King, M.M., Bergstrom, C.T., Correll, S.J., Jacquet, J., and West, J.D., 2017. Men Set Their Own Cites High: Gender and Self-citation across Fields and over Time. Socius 3(2017/01/01), 2378023117738903. DOI= http://doi.org/10.1177/2378023117738903.</bib $>$ <bib id="bib21"><number>[21]</number>Klawe, M., 2013. Increasing Female Participation in Computing: The Harvey Mudd College Story. Computer 46, 3, 56-58. DOI= http://doi.org/10.1109/MC.2013.4.</bib $>$

<bib id="bib22" ><number $>[22]</$ number $>$ Knobloch-Westerwick, S., Glynn, C.J., and Huge, M., 2013. The Matilda Effect in Science Communication:An Experiment on Gender Bias in Publication Quality Perceptions and Collaboration Interest35, 5, 603-625. DOI= http://doi.org/10.1177/1075547012472684.</bib >

$<$ bib id="bib23" $><$ number $>[23]<$ /number $>$ Leslie, S.-J., Cimpian, A., Meyer, M., and Freeland, E., 2015. Expectations of brilliance underlie gender distributions across academic disciplines. Science 347, 6219, 262-265.</bib>

$<$ bib id="bib24" $><$ number $>[24]</$ number $>$ Margolis, J. and Fisher, A., 2003. Unlocking the clubhouse: Women in computing. MIT press. $</$ bib $>$ $<$ bib id="bib25" $><$ number $>[25]</$ number $>$ McKay, D. and Buchanan, G., 2019. Shaking the Tree: Understanding Historic and Future Representation of Women at OzCHI. In Proc Proceedings of the 31st Australian Conference on Human-Computer-Interaction (Fremantle, WA, Australia), Association for Computing Machinery, 412-417. DOI= http://doi.org/10.1145/3369457.3369504.</bib >

$<$ bib id="bib26" $><$ number $>[26]</$ number $>$ McKinnon, R., 2014. Stereotype Threat and Attributional Ambiguity for Trans Women. Hypatia 29, 4, 857-872. $\mathrm{DOI}=$ http://doi.org/10.1111/hypa.12097.</bib $>$

<bib id="bib27"><number>[27]</number>Milkman, K.L., Akinola, M., and Chugh, D., 2015. What happens before? A field experiment exploring how pay and representation differentially shape bias on the pathway into organizations. Journal of Applied Psychology 100,6, 1678-1712. DOI= http://doi.org/10.1037/apl0000022. </bib $>$

<bib id="bib28"><number>[28]</number>Monroe, K., Ozyurt, S., Wrigley, T., and Alexander, A., 2008. Gender Equality in Academia: Bad News from the Trenches, and Some Possible Solutions. Perspectives on Politics 6, 2, 215-233. DOI= http://doi.org/10.1017/S1537592708080572.</bib> $<$ bib id="bib29" $><$ number $>[29]<$ /number $>$ Murphy, M., 2006. Sick building syndrome and the problem of uncertainty: Environmental politics, technoscience, and women workers. Duke University Press. $</$ bib $>$

$\langle$ bib id="bib30" $>\langle$ number $>[30]</$ number $>$ Oleschuk, M. Gender Equity Considerations for Tenure and Promotion during COVID-19. Canadian Review of Sociology. DOI $=$ http $: / /$ doi.org/10.1111/cars. $12295 .</ \mathrm{bib}\rangle$

$<$ bib id="bib31" ><number $>[31]</$ number $>$ Perez, C.C., 2019. Invisible women: Exposing data bias in a world designed for men. Random House. $<$ bib $>$ $<$ bib id="bib32" $><$ number $>[32]<$ number $>$ Pinho-Gomes, A.-C., Peters, S., Thompson, K., Hockham, C., Ripullone, K., Woodward, M., and Carcel, C., 2020. Where are the women? Gender inequalities in COVID-19 research authorship. BMJ Global Health 5, 7, e002922. DOI= http://doi.org/10.1136/bmjgh-2020-002922.</bib>

<bib id="bib33" ><number>[33]</number>Robertson, M., Newell, S., Swan, J., Mathiassen, L., and Bjerknes, G., 2001. The issue of gender within computing: reflections from the UK and Scandinavia. Information Systems Journal 11, 2 (2001/04/01), 111-126. DOI= http://doi.org/l0.1046/j.13652575.2001.00098.x. $</ \mathrm{bib}>$

<bib id="bib34" ><number $>[34]</$ number $>$ Rode, J.A., 2011. A theoretical agenda for feminist HCI. Interacting with Computers 23, 5, 393-400.</bib $>$ <bib id="bib35"><number>[35]</number>Rowe, N., 2018. 'When You Get What You Want, but Not What You Need': The Motivations, Affordances and Shortcomings of Attending Academic/Scientific Conferences. International Journal of Research in Education Science 4, 2, 714-729.</bib $>$ $<$ bib id="bib36"><number>[36]</number>Rowe, N.J.I.J.o.R.i.E. and Science, 2018. 'When You Get What You Want, but Not What You Need': The Motivations, Affordances and Shortcomings of Attending Academic/Scientific Conferences4, 2, 714-729.</bib $>$

$\langle$ bib id="bib37" $>\langle$ number $>[37]</$ number $>$ Surowiecki, J., 2005. The wisdom of crowds. Anchor. $</$ bib $>$

$<$ bib id="bib38"><number>[38]</number>Timperley, C., Sutherland, K.A., Wilson, M., and Hall, M., 2020. He moana pukepuke: navigating gender and ethnic inequality in early career academics' conference attendance. Gender and Education 32, 1 (2020/01/02), 11-26. DOI=

http://doi.org/10.1080/09540253.2019.1633464.</bib> 
<bib id="bib39"><number>[39]</number>Tomkins, A., Zhang, M., and Heavlin, W.D., 2017. Reviewer bias in single- versus double-blind peer review . Proceedings of the National Academy of Sciences 114, 48, 12708-12713. DOI= http://doi.org/10.1073/pnas.1707323114.</bib>

<bib id="bib40" $><$ number $>[40]</$ number $>$ Uhlmann, E.L. and Cohen, G.L., 2007. "I think it, therefore it's true": Effects of self-perceived objectivity on hiring discrimination. Organizational Behavior and Human Decision Processes 104, 2 (2007/11/01/), 207-223. DOI=

http://doi.org/https://doi.org/10.1016/j.obhdp.2007.07.001.</bib >

<bib id="bib41"><number>[41]</number>Wang, W., Bai, X., Xia, F., Bekele, T.M., Su, X., and Tolba, A., 2017. From triadic closure to conference

closure: the role of academic conferences in promoting scientific collaborations. Scientometrics 113, $1(2017 / 10 / 01), 177-193$. DOI=

http://doi.org/10.1007/s11192-017-2468-x.</bib>

$<$ bib id="bib42" $><$ number $>[42]</$ number $>$ Weissmann, J., 2013. The brogrammer effect: women are a small (and shrinking) share of computer workers. In The Atlantic Emerson Collective, Boston, MA.</bib $>$

<bib id="bib43"><number>[43]</number>West, S.M., Whittaker, M., and Crawford, K., 2019. Discriminating Systems: Gender, Race and Power in

AI. $</$ bib $>$

$<$ bib id="bib44" $><$ number $>[44]<$ number $>$ Wilks, J. and Wilson, K., 2015. A profile of the Aboriginal and Torres Strait Islander higher education student population. Australian Universities' Review, The 57, 2, 17.</bib $>$

<bib id="bib45" ><number $>[45]</$ number $>$ Young, I.M., 2011. Justice and the Politics of Difference. Princeton University Press. $</$ bib $>$ 


\section{University Library}

\section{- M M I N E R VA A gateway to Melbourne's research publications}

Minerva Access is the Institutional Repository of The University of Melbourne

Author/s:

McKay, D;Buchanan, G

Title:

Feed the Tree: Representation of Australia-based Academic Women at $\mathrm{HCl}$ Conferences

Date:

2020-12-02

Citation:

McKay, D. \& Buchanan, G. (2020). Feed the Tree: Representation of Australia-based

Academic Women at $\mathrm{HCl}$ Conferences. OzCHI '20: 32nd Australian Conference on HumanComputer-Interaction, ACM. https://doi.org/10.1145/3441000.3441061.

Persistent Link:

http://hdl.handle.net/11343/265946 